\title{
Effect of water absorption on the mechanical properties of carbon fiber reinforced polyoxamide composites
}

\author{
K. Tanaka, T. Hanasaki \& T. Katayama \\ Department of Biomedical Engineering, Doshisha University, Japan
}

\begin{abstract}
Recent environmental pressures on the automotive industries to reduce carbon dioxide emission have led to more production of fuel efficient cars. In order to obtain good gasoline mileage, it is desired to reduce the weight of the car body. Carbon Fiber Reinforced Plastics (CFRP) are attracting attention in the automotive industry for their light-weight attributes. The thermoset plastics like epoxies are mainly used as a matrix of CFRP in the automotive industry. Nonetheless, they cannot be melted or reformed after moulding, making recycling difficult. On the other hand, thermoplastics are recyclable, so they are being expected to be widely applied within the industry. Polyamide 6 (PA6) is expected to be used for the matrix of high performance composites for automobile applications due to its good mechanical properties. Because of the highly hygroscopic properties of PA6, the influence of water absorption on the mechanical properties of Carbon Fiber/Polyamide 6 composites (CF/PA6) have to be taken into account. Recently polyoxamide (PX) resin, which has excellent durability to a water environment, has been developed. In this study, continuous carbon fiber reinforced polyoxamide composites were molded and the influence of water absorption on the mechanical properties of $\mathrm{CF} / \mathrm{PX}$ composites has been clarified.

Keywords: carbon fiber, thermoplastics, polyoxamide (PX), CFRTP, water absorption.
\end{abstract}

\section{Introduction}

Carbon Fiber Reinforced Plastics (CFRP) have advantages in high-specific strength and high-specific modulus, hence the demand of CFRP is increasing in 
the aerospace, automotive and sports industries etc. Especially the thermoset plastics like epoxy are mainly used as a matrix of CFRP in the automotive industry [1]. The FRP using thermosetting resin has bad productivity, and it cannot be melted or reformed after moulding, making recycling difficult. On the other hand, Carbon Fiber Reinforced Thermoplastics (CFRTP) is recyclable, good in productivity and impact strength thus it is expected to be widely applied within the industry [2]. In the thermoplastics resin, Polyamide (PA) is expected to be used for the matrix of high performance composites for automobile applications due to its good interfacial properties to carbon fiber. Although PA has good interfacial properties to carbon fiber compared to other superior engineering plastics [3], PA is well known as the highly hygroscopic thermoplastics because of having an amide bond $[4,5]$. The influence of water absorption on the mechanical properties of CF/PA composite has been clarified and we have anxiety about using CF/PA composite for a long time [4].

Recently in order to solve this problem, polyoxamide (PX) resin, which has excellent durability to water environment, has developed. PX possesses a characteristic as low water absorption because it has successive amide bond in the trans position [6]. So far there has been no report of CF/PX composites. Therefore, it is important to clarify the influence of water absorption on the mechanical properties of CF/PX composites.

In this study, the influence of water absorption on the mechanical properties of CF/PX and CF/PA6 composites and the influence of water absorption on $\mathrm{CF} / \mathrm{PX}$ and CF/PA6 interfacial shear strength will be clarified.

\section{Materials and experimental procedure}

\subsection{Material}

Non-crimp stitched carbon fabric (NCF, $300 \mathrm{~g} / \mathrm{m}^{2}$, [0 $\left./ 90^{\circ}\right]$ ), using PAN-based carbon fibers, being stitched together by polyester sewing thread, were used as the reinforcing fabric.

Non-woven fabric (Prototype, Kuraray Co., Japan) for PA6 (1013B, UBE Ltd., Japan) and for PX (4000B, UBE Ltd., Japan), was used as the matrix. The weight per unit area of PA6 and PX is $49 \mathrm{~g} / \mathrm{m}^{2}$ and $50 \mathrm{~g} / \mathrm{m}^{2}$, respectively.

\subsection{Moulding method of CF/PA6 and CF/PX composites}

The non-crimp stitched carbon fabric and PA6 or PX non-woven fabrics were stacked in six layers. High speed compression moulding system was used as the molding method of CF/PA6 and CF/PX composite [7]. The number of carbon fabric and each non-woven fabrics was prepared to obtain the desirable fiber volume fraction $\left(V_{f}\right)$. Moulding pressure and maximum temperature holding time were set for $2 \mathrm{MPa}$ and 120 s, respectively. Moulding temperatures of CF/PA6 and $\mathrm{CF} / \mathrm{PX}$ composite were set for $260^{\circ} \mathrm{C}$ and $300^{\circ} \mathrm{C}$, respectively. All the molding conditions are shown in Table 1 . After moulding, the samples are aircooled at laboratory temperature. The test specimens for bending tests were cut 
out from moulded composite. The length, width and thickness of CF/PA6 and $\mathrm{CF} / \mathrm{PX}$ composite specimens were $100 \mathrm{~mm}, 15 \mathrm{~mm}$ and $2 \mathrm{~mm}$ respectively.

Table 1: $\quad$ Molding conditions of composites.

\begin{tabular}{|c|c|c|c|c|}
\hline & $\begin{array}{c}\text { Pressure } \\
{[\mathrm{MPa}]}\end{array}$ & $\begin{array}{c}\text { Temperature } \\
{\left[{ }^{\circ} \mathrm{C}\right]}\end{array}$ & $\begin{array}{c}\text { Holding } \\
\text { time }[\mathrm{s}]\end{array}$ & $\begin{array}{c}\mathrm{V}_{\mathrm{f}} \\
{[\%]}\end{array}$ \\
\cline { 1 - 3 } CF/PA6 & \multirow{2}{*}{2} & 260 & \multirow{2}{*}{120} & 50 \\
\cline { 1 - 1 } CF/PX & 2 & 300 & & 50 \\
\cline { 3 - 4 } & & & 2600 &
\end{tabular}

\subsection{Mechanical test}

To evaluate the effect of water absorption against immersion time on the bending fracture properties for CF/PA6 and CF/PX composite, water absorption test was performed. Specimens were immersed in distilled water at $80^{\circ} \mathrm{C}$. The specimen was weighted by an electronic balance since took out a specimen at specific time from the water and wiped off surface water. The water gain, C (Wt. \%), was calculated by the following equation.

$$
C=\frac{m-m_{0}}{m_{0}} \times 100
$$

where $m_{0}$ : specimen weight before the test and $m$ : specimen weight.

The bending tests were conducted by the universal testing machine (Instron5566, Instron Co., USA). The bending tests were conducted following the recommended testing procedures as described in JIS-K7073. More than 5 composite specimens were examined for each condition. The fracture side view of the composite specimens was observed by optical microscope (OLYMPUS BX51M, OLYMPUS Co., Japan).

\subsection{Single fiber pull-out test}

To understand the interfacial shear strength of CF/PX and CF/PA6, single fiber pull-out tests were conducted using a testing machine for micro material (MMT$11 \mathrm{~N}$, Shimadzu Co., Japan) [8-10]. The PAN-based carbon fibers were used for a single fiber pull-out test, each resin was used for a matrix and polyester thin film was used as a tab. Figure 1 shows the making procedure of pull-out model specimen. First, after a single fiber was glued to the tab with adhesive, the tab was attached to a micromanipulator. Next, the resin was placed on the aluminum plate which was heated at each molding temperature condition (CF/PA6 model specimen: $260^{\circ} \mathrm{C}, \mathrm{CF} / \mathrm{PX}$ model specimen: $300^{\circ} \mathrm{C}$ ). Finally, the single fiber was embedded to the matrix using the micromanipulator, and it was air-cooled. Some specimens were immersed in distilled water at $80^{\circ} \mathrm{C}$ for 100 hours, 400 hours, and others were kept in laboratory air. These specimens will be referred to as 100 hours wet model specimen, 400 hours wet model specimen, dry model specimen, respectively. After chucking a specimen, the supporting part of the tab 
was cut and the pull-out test was conducted with a constant displacement rate of $1.67 \times 10^{-6} \mathrm{~mm} / \mathrm{s}(0.1 \mathrm{~mm} / \mathrm{min})$. For the calculation of the interfacial strength, the cross-section areas of each pull-pout tested fiber were measured by scanning electron microscope. Figure 2 shows the SEM image of the embedded length and fiber diameter. The interfacial shear strength was calculated by the following equation (2).

$$
\tau=\frac{F_{\max }}{\pi d l}
$$

where $F_{\max }$ : the maximum load, $d$ : fiber diameter and $l$ : embedded length.

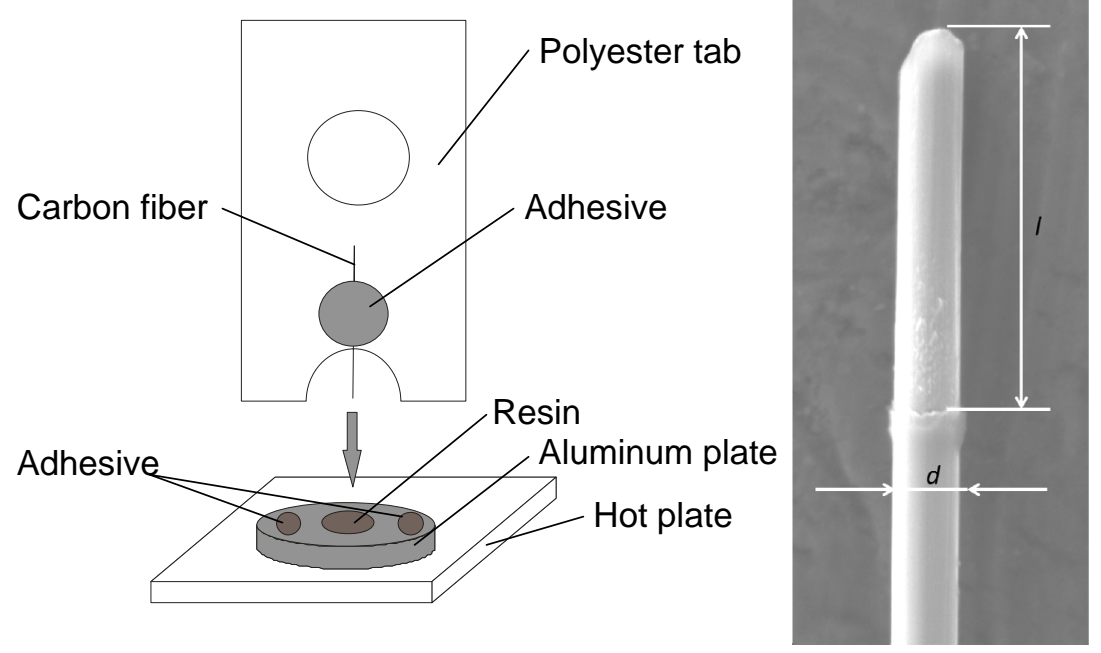

Figure 1: Making procedure of Figure 2: SEM observations of pull-out specimen. the embedded length and fiber diameter.

\section{Results and discussions}

\subsection{Water absorption property}

The relationship between immersion time and water gain of the composite is shown in Figure 3. The water gain of CF/PA6 composite is significantly higher in the first 25 hours, compared to that of CF/PX composite. The saturation of CF/PA6 composite and CF/PX composite were reached after about 25 hours and 225 hours respectively. At this point the percentage increase in the water gain of $\mathrm{CF} / \mathrm{PA} 6$ composite and $\mathrm{CF} / \mathrm{PX}$ composite were $2.8 \%$ and $1.1 \%$ respectively. As wet specimens were prepared to be immersed in distilled water at $80^{\circ} \mathrm{C}$ for 400 hours in this study, it means that water diffuses enough to the entire test specimen. 


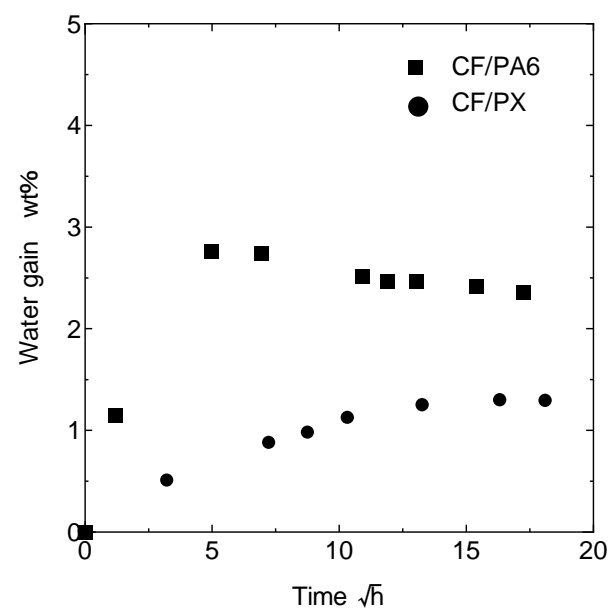

Figure 3: Water absorption curve of composites.

\subsection{Fiber/matrix interfacial properties}

Figure 4 shows the results of the fiber/matrix interfacial shear strength of CF/PA6 model specimen and CF/PX model specimen obtained by the single fiber pull-out tests. The interfacial shear strength of model specimens were calculated by using the equation (2). Interfacial shear strength of the dry CF/PA6 model specimens, 100 hours wet CF/PA6 model specimens, 400 hours wet $\mathrm{CF} / \mathrm{PA} 6$ model specimens were 45.6MPa, 27.4MPa, and 20.2MPa, respectively. On the other hand that of the dry CF/PX model specimens, 100 hours wet CF/PX

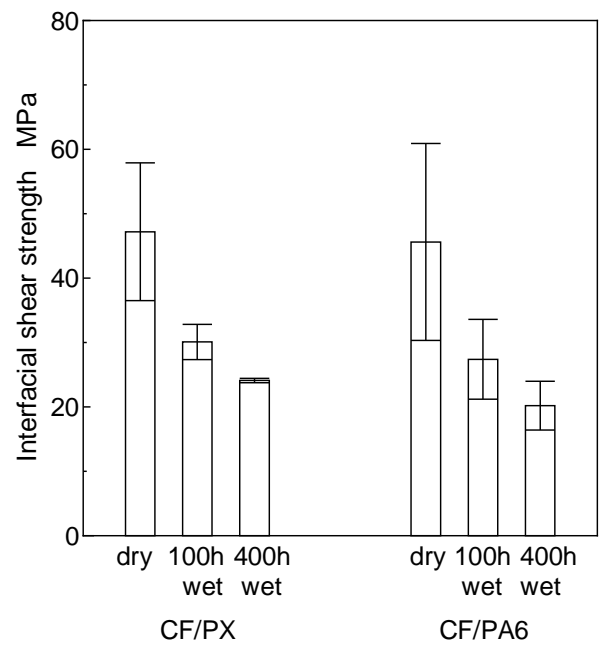

Figure 4: $\quad$ Fiber/matrix interfacial shear strength of each model specimen. 
model specimens, 400 hours wet $\mathrm{CF} / \mathrm{PX}$ model specimens were $47.2 \mathrm{MPa}$, 30.1MPa, 24.1MPa, respectively. Interfacial shear strength of both model specimens have decreased as water absorption time increases. At 400 hours wet condition, interfacial shearing strength of $\mathrm{CF} / \mathrm{PX}$ model specimens have about 1.2 times that of CF/PA6 model specimen.

\subsection{Bending test of CFRTP}

Figure 5 shows the stress-strain curves of composites and Figure 6 presents the bending strength of composites. According to Figure 5, both dry CF/PA6 and $\mathrm{CF} / \mathrm{PX}$ composite fractured in brittle manner when it reached the maximum fracture load with increasing load to a linear target. The $100 \mathrm{~h}$ wet and $400 \mathrm{~h}$ wet specimens of CF/PA6 composite fractured gradually and the maximum fracture load of wet specimens of CF/PA6 composite decreases with the increases of strain. As against to CF/PA6 composite, $100 \mathrm{~h}$ wet and $400 \mathrm{~h}$ wet specimens of $\mathrm{CF} / \mathrm{PX}$ composite fractured in brittle manner.

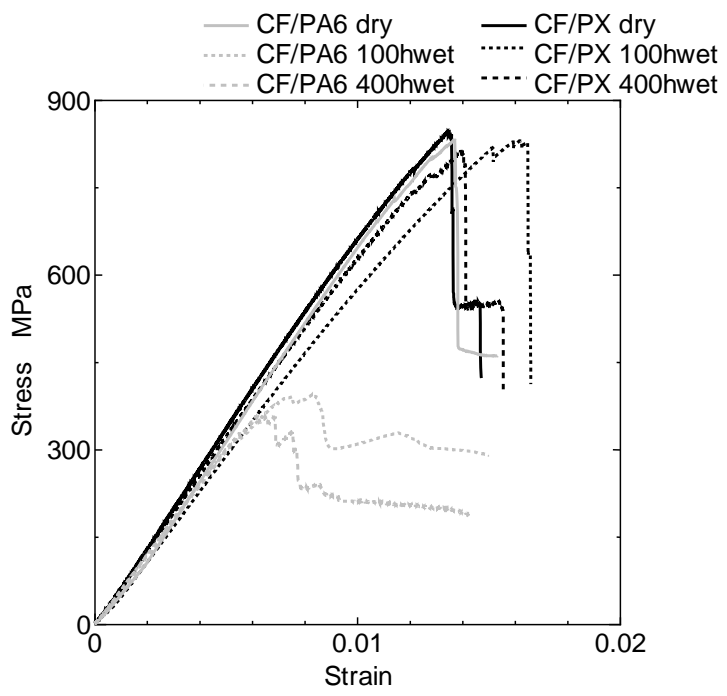

Figure 5: $\quad$ Stress-strain curve.

Figure 6 shows the bending strength for each specimen. Bending strength of the dry CF/PA6 composite, the 100 hours wet CF/PA6 composite, the 400 hours wet CF/PA6 composite were $804 \mathrm{MPa}$, 358MPa, and 380MPa, respectively. On the other hand, bending strength of the dry CF/PX composite, the 100 hours wet $\mathrm{CF} / \mathrm{PX}$ composite, the 400 hours wet $\mathrm{CF} / \mathrm{PX}$ composite were $858 \mathrm{MPa}$, $866 \mathrm{MPa}$, $830 \mathrm{MPa}$, respectively. 


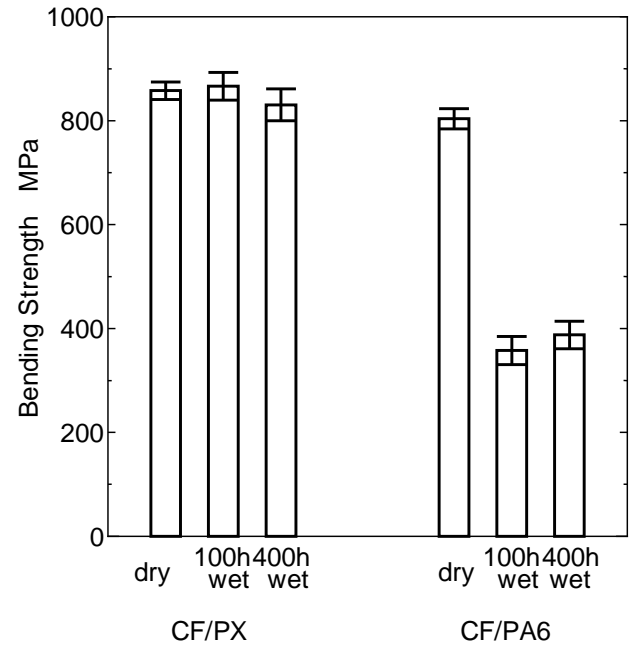

Figure 6: Bending strength of composites.

\subsection{Discussion}

Figure 7 shows the side views of dry and $400 \mathrm{~h}$ wet composite specimen for both $\mathrm{CF} / \mathrm{PA}$ composite and CF/PX composite. As for the 400 hours wet CF/PA6
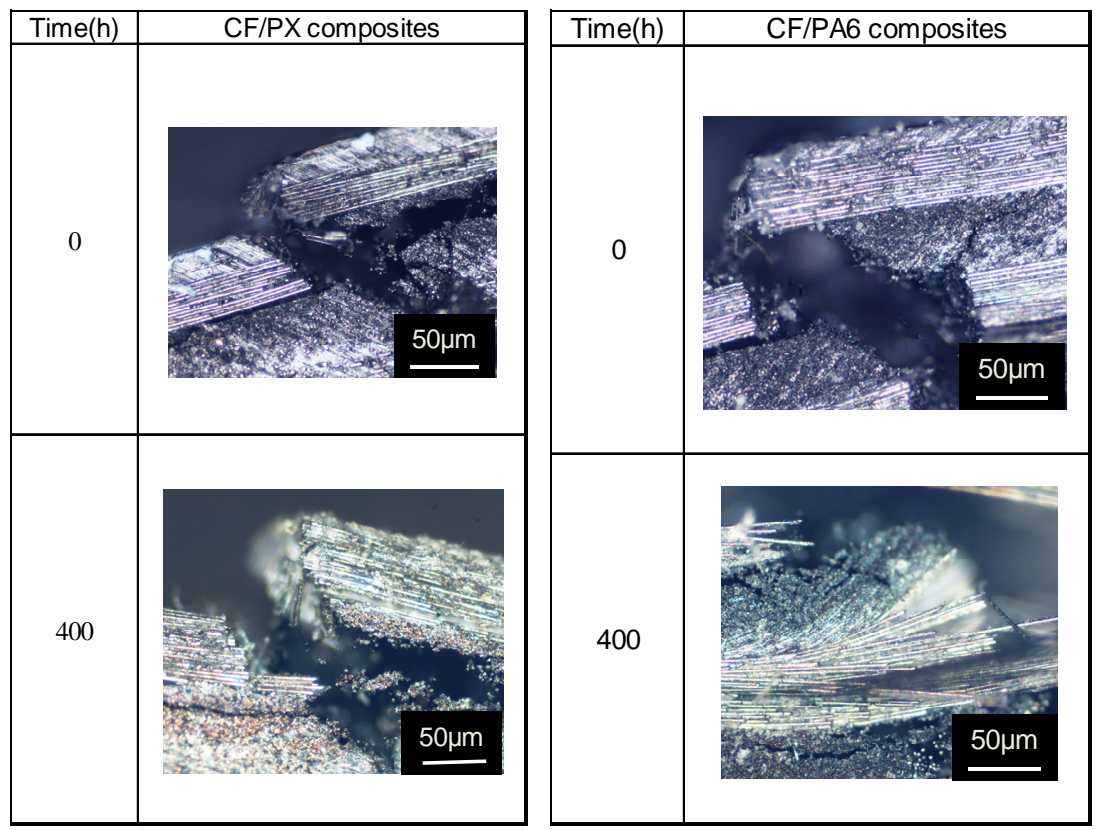

Figure 7: $\quad$ Side fracture surface of composites. 
composite, separated fibers were observed. On the other hand, CF/PX composite have the settlement of the fibers unlike in the case of CF/PA6 composite. In this study, water diffuses enough to both composites in 400 hours describing ahead in paragraph 3-3. It's determined that the difference of interfacial strength with resin correspond to the difference of fracture mechanism.

\section{Conclusion}

In this study, the influence of water absorption on the mechanical properties of $\mathrm{CF} / \mathrm{PX}$ and $\mathrm{CF} / \mathrm{PA} 6$ composites and the influence of water absorption on $\mathrm{CF} / \mathrm{PX}$ and CF/PA6 interfacial shear strength will be clarified. The investigation yielded the following conclusions:

1. The water gain of CF/PX composite and CF/PA6 composite were saturated at $1.1 \%$ and $2.8 \%$ respectively.

2. Interfacial shear strength of the dry CF/PA6 model specimens, 100 hours wet CF/PA6 model specimens, 400 hours wet CF/PA6 model specimens were 45.6MPa, 27.4MPa, and 20.2MPa, respectively. On the other hand that of the dry CF/PX model specimens, 100 hours wet CF/PX model specimens, 400 hours wet CF/PX model specimens were $47.2 \mathrm{MPa}, 30.1 \mathrm{MPa}, 24.1 \mathrm{MPa}$, respectively. Interfacial shear strength of both model specimens had decreased as water absorption time increases.

3. The bending strength of the CF/PA6 composite showed a tendency to decrease as water absorption time increases. On the other hand, the bending strength of $\mathrm{CF} / \mathrm{PX}$ composite presented a tendency to remain static as the water absorption time increases.

\section{Acknowledgements}

This study was partially supported by the High Technological Research Project on "Research and Development Center for Advanced Composite Materials" of Doshisha University and Ministry of Education, Culture, Sports, Science and Technology, Japan

\section{References}

[1] Jacob, A., Reinforced Plastics, Vol. 48, No. 2, pp. 26-32, 2004.

[2] Offringa, A. R., Thermoplastic composite - rapid processing applications, Composite Part A, Vol. 27A, pp. 329-336, 1996.

[3] Beckwith, S. W., Thermoplastic composite resin matrices, Sampe Journal, Vol. 44, No.1, pp. 70-71, 2008.

[4] Boukal, I., Effect of water on the mechanism of deformation of nylon6, Journal of applied polymer science, Vol. 11, pp. 1483-1494, 1967.

[5] Nishioka, T., Polyamide6, Kogyo Zairyo, Vol. 37, No. 6, pp. 12-17, 1989.

[6] UBE, Technological material. 
[7] Tanaka, K., Katayama, T., and Uno, K., Eco-efficient Manufacturing Process of Fiber Reinforced Thermoplastic, High Performance Structures and Materials IV, WIT Transactions on the Built Environment-97, Vol. 97, pp. 203-210, 2008.

[8] DiFrancia, C., Ward, Thomas C., and Claus, R. O., The single-fiber pull-out test, Composites: Part A, Vol. 27, pp. 597-612, 1996.

[9] Zhou, X. -F., Nairn, J. A., Wagner, H. D., Fiber-matrix adhesion from the single-fiber composite test: nucleation of interfacial debonding, Composites: Part A, Vol. 30, pp. 1387-1400, 1999.

[10] Tanaka, K., Minoshima, K., Grela, W., and Komai, K., Characterization of the aramid/epoxy interfacial properties by means of pull-out test and influence of water absorption, Composites Science and Technology 62, pp. 2169-2177, 2002. 